Revue d'histoire de l'Amérique française

FBS REVUE D.HISTOIRE DE L'AMÉRIQUE FRANÇAISE

\title{
Relevé des principaux articles de Margry sur l'Amérique
}

\section{Louis-P. Cormier}

Volume 27, numéro 1, juin 1973

URI : https://id.erudit.org/iderudit/303233ar

DOI : https://doi.org/10.7202/303233ar

Aller au sommaire du numéro

\section{Éditeur(s)}

Institut d'histoire de l'Amérique française

\section{ISSN}

0035-2357 (imprimé)

1492-1383 (numérique)

Découvrir la revue

\section{Citer cette note}

Cormier, L.-P. (1973). Relevé des principaux articles de Margry sur l'Amérique. Revue d'histoire de l'Amérique française, 27(1), 76-78.

https://doi.org/10.7202/303233ar d'utilisation que vous pouvez consulter en ligne.

https://apropos.erudit.org/fr/usagers/politique-dutilisation/ 
II

\section{RELEVÉ DES PRINCIPAUX ARTICLES DE MARGRY SUR L'AMERIQUE}

Pierre Margry s'est intéressé particulièrement à l'histoire des navigations françaises et des établissements coloniaux des $X V I^{e}, X V I I^{e}$ et $X V I I I^{e}$ siècles. Il reste connu par les livres qu'il a laissés; en Amérique, principalement par les six volumes de documents: Découvertes et Etablissements des Français dans l'Ouest et dans le Sud de l'Amérique Septentrionale, 1614-1754 (Paris, 1876-1888). Il a écrit aussi de nombreux articles aujourd'hui impossibles à retracer. Certains de ces articles ont fait du bruit: Margry s'en servait comme ballons d'essai pour lancer de nouvelles interprétations de l'histoire. En l'absence de bibliographie des travaux de Margry, la lettre qui suit, dans laquelle il fait lui-même le relevé de ses principaux articles concernant l'Amérique, me semble intéressante et pourrait, je crois, être utile aux chercheurs.

L'original de ce document se trouve dans la collection Edward E. Ayer, ms. 563, à la Newberry Library de Chicago.

Le destinataire et la date sont inconnus. Les indications contenues dans la lettre permettent de fixer des dates limites: elle n'a pas pu être écrite avant le 22 mai 1867, ni après le mois de mai 1879, date où Margry quitte son appartement de la rue du Mont Thabor.

LOUIS-P. CORMIER

Département des langues modernes

Université de Lethbridge (Alberta) 


\section{Monsieur}

Vous me faites l'honneur de me demander au nom d'un de vos correspondans de New York quels articles j'ai publiés sur l'Histoire des Etats Unis Et notamment celui que J'ai donné en 1862 au Journal de l'Instruction Publique.

M. votre correspondant fait sans doute allusion ici à mon Etude intitulée Les Normands dans les vallées de l'Ohio et $d u$ Missississpi. Cette Etude a paru pièce a pièce dans le Journal Général de l'Instruction Publique, le 30 juillet, le 20 et le 30 aout et le 17. $7^{\text {bre }} 1862$.

Dans le même Journal, publié par La Librairie Paul Dupont, se trouvent En 1866 Les Entreprises de Louis Joliet dans l'Amérique du Nord. Cette Etude a paru les 29 aout, 23. $8^{\text {bre }}$, le 7. $9^{\text {bre }}$ le $21.9^{\text {bre }}$, le $5 \mathrm{X}^{\text {bre }}$, le 26 . $\mathrm{X}^{\text {bre }} 1866$, le 13 fevrier 1867 . Le 10 avril ou le 17 ; le $1^{\text {er }}$ et le 22 mai.

Je pourrais vous citer encore dans le Moniteur du 14. $7^{\text {bre }}$ et Novembre ou $\mathrm{X}^{\text {bre }} 1852$ Les Varennes de la Verendrye et les Francais aux Montagnes Rocheuses sous Louis $X V{ }^{1}$

En 1854 également dans le Moniteur Les Indiens Renards et la nation du feu au Détroit PontChartrain des Deux Lacs ${ }^{2}$ En 1859. La navigation du Mississipi Et les Precurseurs de Fulton aux Etats Unis, qui ont fait plusieurs articles ${ }^{3}$

J'ai donné aussi une Notice sur Samuel de Champlain mais comme c'était loin de mes yeux qu'on la imprimée et qu'elle a Eté mutilée par les Journaux de Saintonge, Je ne l'ai pas signée, ne prenant du reste en souci que la préoccupation que Je voulais donner a la province d'une gloire dont elle n'avait pas assez conscience. Je suis parvenu là dessus à ce que je voulais, Et Les actes De La Commission des arts et monumens de la Charente Inferieure ( $\mathrm{N}^{\circ} 9$ du recueil) contiennent cette Etude.

Enfin J'ai donné à la Seconde Edition de la Biographie Universelle de Michaud un article sur Menou d'Aunay Charnisay l'un des Pionniers de l'Acadie.

Je doute, Monsieur, que vous puissiez trouver tous les journaux où sont ces articles on me les a déjà demandés plusieurs fois

1 Dans une lettre du 11 sept. 1888 à Parkman il donne comme dates: le 4 septembre et le 7 novembre 1852 .

2 D'après une lettre du 6 février 1889 à Parkman, ces articles ont paru le 14 , le 16 et le 17 novembre 1854 .

3 Dans l'étude de 1862 , la première mentionnée dans cette lettre, à la page 702 on lit cette note: "Voir le Moniteur, 7 et 29 mars, 16 et 19 avril 1859 , l'Etude que j'ai donnée sur les navigations de Mississippi et les précurseurs de Fulton aux Etats-Unis". 
inutilement ainsi que d'autres sur les Antilles et sur les Indes, l'Afrique. - Mais vous pouvez dire à votre correspondant qu'un jour qui sera prochain s'il plait a Dieu, je reunirai ces articles corrigés à d'autres etudes inedites qui formeront un Ensemble Interessant et nouveau dans l'Histoire, ${ }^{4}$ comme L'ecrivain dont vous m'avez envoyé le Livre veut bien le donner à penser.

Veuillez agréer, Monsieur, l'assurance de ma Consideration distinguée

Pierre Margry

11. Rue du Mont Thabor

${ }^{4}$ A ma connaissance, ce projet n'a pas été réalisé. 